\title{
THE INFLUENCE OF TEMPERATURE ON THE EVOLU. TION OF HYDROGEN SULPHIDE FROM VULCANIZED RUBBER
}

\author{
By A. D. Cummings
}

\section{ABSTRACT}

Evolution of hydrogen sulphide from vulcanized rubber containing 8 to 32 per cent sulphur has been measured when the temperature of the specimens was raised step by step from $105^{\circ}$ to $265^{\circ} \mathrm{C}$., and the time intervals kept equal. The same sample of each compound was employed throughout the whole temperature range. The rate of decomposition increases as the temperature is raised, except in the case of the compounds containing the higher percentages of sulphur, when it passes through a maximum.

The loss of hydrogen sulphide has also been determined for four different compounds containing $4,10,18$, and 32 per cent sulphur when samples were heated for 200 hours at $136^{\circ} \mathrm{C}$, and also when other samples of these compounds were maintained for the same length of time at $220^{\circ} \mathrm{C}$. In each case, the rate of decomposicion decreases rapidly at first, but after several days' heating, the decrease becomes relatively slow. In general, the rate increases with temperature and with increasing sulphur content. Other products evolved are moisture and organic compounds.

The data presented in this paper supplement and confirm previous results on the evolution of hydrogen sulphide from vulcanized rubber and indicate at what i temperatures direct thermal decomposition of different rubber-sulphur compounds will become significant. No mechanism to explain the chemical changes involved is suggested. This question is worthy of further investigation.

\section{CONTENTS}

1. Introduction

II. Preparation of specimens _... 165

III. Apparatus and procedure for determining the hydrogen sulphide

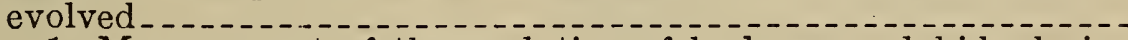

1. Measurement of the evolution of hydrogen sulphide during step-by-step heating.

2. Measurement of the evolution of hydrogen sulphide at con-

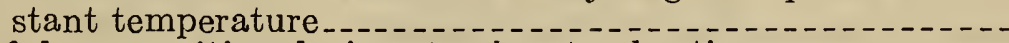

IV. Results of decomposition during step-by-step heating

V. Results of decomposition at constant temperature

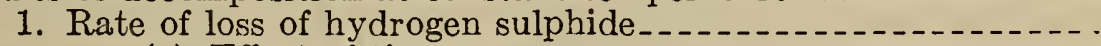

(a) Effect of time.....

(b) Effect of temperature

(c) Effect of composition of samples.............

2. Other decomposition products and moisture

VI. Characteristics of the rubber after heating

VII. Discussion.

\section{INTRODUCTION}

This paper presents the results of measurements of the evolution of hydrogen sulphide from rubber-sulphur compounds heated at various temperatures. Determination of the amount of hydrogen sulphide produced under different conditions was used to measure 
the degree of decomposition of the rubber. Two types of experiments were carried out: (1) Samples of vulcanized rubber containing 8 to 32 per cent sulphur were heated for 8-hour intervals at 13 temperatures between $105^{\circ}$ and $265^{\circ} \mathrm{C}$., and (2) samples having sulphur contents of $4,10,18$, and 32 per cent were maintained for about 200 hours at constant temperature, one set of specimens at $136^{\circ}$ and another group at $220^{\circ} \mathrm{C}$.

These measurements of deterioration were undertaken in connection with an investigation on the electrical properties of vulcanized rubber at relatively high temperatures. During these experiments, samples of rubber-sulphur compounds had been subjected to a wide range of temperatures. Time of exposure to each temperature had been about eight hours. The purpose of the present work was to determine when the sulphur content of a specimen had changed sufficiently to affect its dielectric constant and power factor by a measurable amount. In order to approximate the conditions under which the electrical tests were made, it was necessary to determine the amount of decomposition when rubber vulcanized with 8 to 32 per cent. sulphur was heated for successive intervals of eight hours each at temperatures changed in unequal steps from $105^{\circ}$ to $265^{\circ} \mathrm{C}$. To make this information more complete and to obtain additional data which could be compared with previous investigations, the work was extended to include determinations of the loss of hydrogen sulphide from vulcanized rubber heated for a long time at constant temperature. The electrical properties of the whole series of rubbersulphur compounds is the subject of a separate investigation at this bureau, and will be reported in another paper.

Many investigators have shown that hydrogen sulphide is associated with the vulcanization of rubber and with its subsequent deterioration during aging. Stevens and Stevens have noted the evolution of hydrogen sulphide during the vulcanization of ebonite at temperatures above $70^{\circ} \mathrm{C}$. Webster, Fry, and Porritt have shown that ebonite evolves hydrogen sulphide at ordinary temperatures as well as when heated and have measured the rate of decomposition at several temperatures. Wolesensky has found that both soft and hard rubber lose hydrogen sulphide at all temperatures above $25^{\circ} \mathrm{C}$. For more details of previous investigations on this problem during the last few years, the reader is referred to the papers by the authors mentioned. ${ }^{1}$ A review of the literature up to 1929 is given in the paper by Wolesensky.

The results described in this paper represent a single set of measurements of the evolution of hydrogen sulphide when compounds of purified rubber and sulphur were heated under different conditions of time and temperature. Possible effects or variations which might be encountered with rubber samples made at different times or prepared in different forms for exposure to the heat, or with other changes in experimental conditions were not investigated. The results show the loss of hydrogen sulphide when rubber-sulphur compounds representative of the whole series from soft to hard rubber were heated step by step from $105^{\circ}$ to $265^{\circ} \mathrm{C}$., and also when heated for 200 hours at $136^{\circ}$ and at $220^{\circ} \mathrm{C}$.

\footnotetext{
1 Edward Wolesensky, B. S. Jour. Research, vol. 4, p. 501, 1930; Rubber Chem. Tech., vol. 3, p. 386, 1930. J. D. Fry and B. D. Porritt, India Rubber J., vol. 78, p. 307, 1929. D. M. Webster and B. D. Porritt, India Rubber J., vol. 79, p. 239, 1930; Rubber Chem. Tech., vol. 3, p. 618, 1930. H. P. Stevens and W. H. Stevens, J. Soc. Chem. Ind., vol. 50, p. 397T, 1931.
} 


\section{PREPARATION OF SPECIMENS}

The rubber specimens were prepared from protein-free rubber hydrocarbon and sulphur. The rubber hydrocarbon was obtained from latex by digestion with hot water and extraction with water and alcohol, in accordance with the method described by McPherson, ${ }^{2}$ which gives a purified material containing about 99.5 per cent hydrocarbon. A master batch of rubber and sulphur was made and portions of this were blended with fresh rubber hydrocarbon to give any sulphur content desired. The specimens were prepared by pressing samples of these rubber-sulphur mixtures between thin aluminum plates separated by a spacer $1.25 \mathrm{~mm}$ in thickness. The specimens were then placed in an autoclave and vulcanized for 40 hours at $141^{\circ} \mathrm{C}$. under pressure of carbon dioxide. The long period of vulcanization

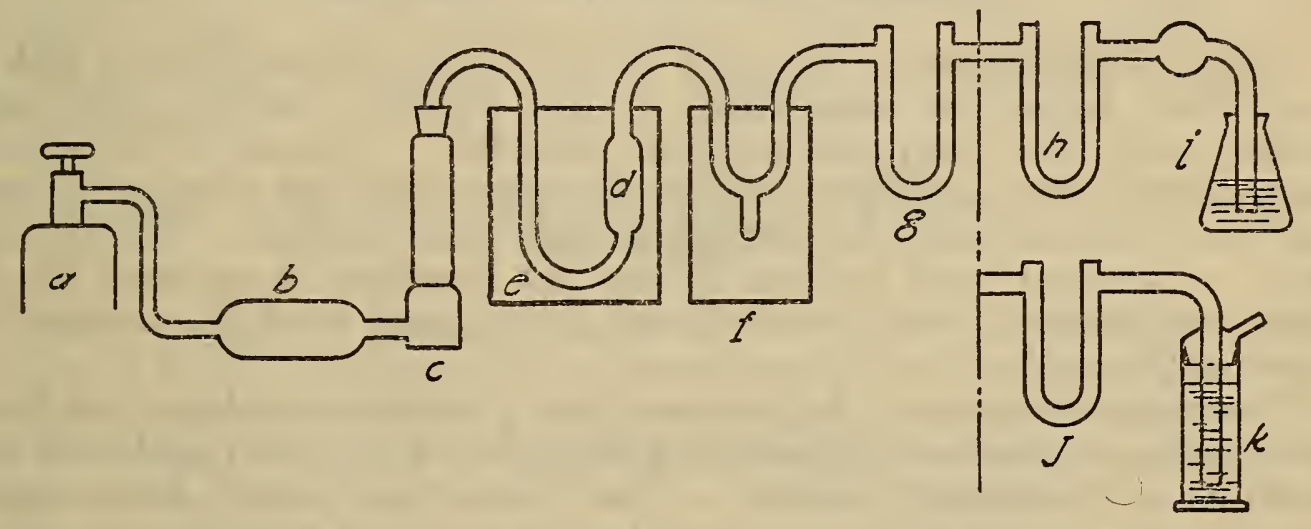

FIGURE 1.-Apparaius used for measurement of decomposition of vulcanized rubber

$a$, cylinder of commercial hydrogen to provide an inert atmosphere and sweep out products evolved while the rubber is heated.

$b$, concentrated alkaline pyrogallol solution on glass wool to absorb traces of oxygen.

$c$, tower containing calcium chloride and magneium perchlorate to dry the gas stream.

$d$, glass tube containing the rubber sample cut into strips.

$e$, oil bath, electrically heated and thermostatically controlled.

$f$, trap in ice-salt freezing mixture to collect any volatile liquids. $g, U$ tube containing magnesium perchlorate to absorb moisture given off from the rubber.

$h, \cup$ tube containing saturated potassium hydroxide solution on glass wool to absorb hydrogen sulphide, protected at each end by drying agent to prevent loss of moisture from the tube.

$i$, protective drying tube and bubble counter.

NOTE.-In some cases lead acetate solution was used as an absorber for hydrogen sulphide. This is indicated by the gas-washing bottle, $k$, preceded by the drying tube, $j$, to prevent back diffusion of moisture into the weighed drying tube, $g$.

resulte'd in a product which contained practically no free sulphur in the soft and medium hard rubber ranges. In the case of pure hard rubber, analyses on different samples of stock containing 32 per cent sulphur showed from 0.5 to 0.8 per cent free sulphur. In the present experiments, the 32 per cent sample was the only one to show a deposit of sublimed sulphur.

\section{APPARATUS AND PROCEDURE FOR DETERMINING THE FYDROGEN SULPHIDE DISSOLVED}

The essential features of the apparatus were a supply of inert gas, a tube to hold the rubber sample, a constant temperature bath, and an absorber for the hydrogen sulphide. The individual parts of the apparatus are indicated and described in Figure 1.

2A. T. McPherson, A Method for the Purification of Rubber and Properties of the Purified Rubber B. S. Jour. Research, vol. 8 (RP449), p. 751, 1932. 
The general method chosen for measuring the deterioration of vulcanized rubber when heated was determination of the amount of hydrogen sulphide evolved. This determination was carried out in two ways: (1) the hydrogen sulphide was absorbed in lead acetate solution and the lead sulphide collected and weighed, and (2) the hydrogen sulphide was absorbed by saturated potassium hydroxide solution contained in a tube which could be weighed directly. Both methods were equally satisfactory under appropriate conditions. Absorption in lead acetate is preferable when a very small amount of hydrogen sulphide is to be measured, but when much lead sulphide is formed this method becomes exceedingly time-consuming on account of slow filtration.

\section{MEASUREMENT OF THE EVOLUTION OF HYDROGEN SULPHIDE DURING STEP-BY-STEP HEATING}

The decomposition in this part of the work was carried out with a simplified apparatus consisting of gas supply, sample tube and heater, trap, and hydrogen sulphide absorber. In order to duplicate more nearly the conditions during the electrical test when the inert gas was not purified, the purifying train was omitted. The drying tube, $g$, was not used because it was not intended to account for all products formed. Only sections $a, d, e, f$, and $k$ of the apparatus were employed.

The tubes containing 5-gram samples of rubber in strips cut from the specimens previously described were placed in the oil bath and the stream of hydrogen ${ }^{3}$ started. The bath was heated from room temperature up to $105^{\circ} \mathrm{C}$. where it was held for eight hours. The absorber containing lead acetate solution was then changed, provided any precipitated lead sulphide was visible, and the temperature was raised to $115^{\circ}$. The lead sulphide formed was collected by filtration through a Gooch crucible, washed, dried, and weighed. This procedure was repeated step by step every eight hours at 13 temperatures between $105^{\circ}$ and $265^{\circ}$, with samples containing from 8 to 32 per cent sulphur. All samples were heated for eight hours at each temperature before being raised to the next higher temperature. It was already known that the electrical properties of rubber containing less than 8 per cent sulphur were not changed a significant amount by loss of sulphur when heated under these conditions, consequently the experiments were begun with the 8 per cent compound. Temperatures below $100^{\circ}$ did not cause a change in sulphur content sufficient to be detected in the electrical measurements on a specimen containing the maximum amount, 32 per cent, of sulphur, therefore $105^{\circ}$ was selected as the initial temperature.

\section{MEASUREMEINT OF THE EVOLUTION OF HYDROGEN SULPHIDE AT CONSTANT TEMPERATURE}

The apparatus was used complete as described for this part of the investigation, and both methods for the absorption of the hydrogen sulphide were employed. The specimen tubes containing 20 to $50 \mathrm{~g}$

\footnotetext{
3 No significant error was introduced by reaction of the hydrogen with any small amount of free sulphur in the rubber. The rate of reaction of hydrogen with sulphur is relatively slow at the highest temperature used in the present experiments. (See J. W. Mellor, A Comprehensive Treatise on Inorganic and Theoretical Chemistry, vol 10, pp. 117 fi., 1930.) Furthermore, an experiment in which steam was used as the inert gas gave substantially the same rate of evolution of hydrogen sulphide as was obtained with hydrogen (unpublished work of A. T. McPherson).
} 
of rubber were set up at room temperature outside the oil bath. While the bath was being heated to the temperature desired, the apparatus was swept with hydrogen to displace air. The tubes for absorption of moisture and of hydrogen sulphide, when potassium hydroxide was used, were removed, weighed, and then replaced. The tubes containing the rubber samples were next immersed in the hot oil, and the hydrogen stream was adjusted to about one bubble per second. The hydrogen sulphide was measured at intervals by weighing the $U$-tube absorbers directly or by determining the amount of lead sulphide formed. The amount of moisture and volatile oils was determined only at the end of the experiment. This served to account for the entire loss in weight of the samples. The loss of hydrogen sulphide was determined for four rubber compounds containing $4,10,18$, and 32 per cent sulphur when samples were heated for about 200 hours at $136^{\circ}$ C., and also when other samples were heated at $220^{\circ} \mathrm{C}$. for the same length of time. The temperature of the oil bath was held within $\pm 1^{\circ}$ at the former temperature and $\pm 3^{\circ}$ at the latter.

\section{RESULTS OF DECOMPOSITION DURING STEP-BY-STEP HEATING}

The evolution of hydrogen sulphide from vulcanized rubber containing 8 to 32 per cent sulphur when heated in the 8-hour stepwise manner increases with rising temperature, with the exception that the loss from the compounds containing the higher percentages of sulphur passes through a maximum. In view of the large change in sulphur content during heating, this is not surprising. The amount of hydrogen sulphide evolved in an 8-hour interval at each temperature is shown in Figure 2.

The change in sulphur content calculated from the loss of sulphur as hydrogen sulphide between $105^{\circ}$ and each higher temperature is given in Figure 3. These values for the sulphur content are not identical with those which would be determined by analysis of a sample of rubber taken at each temperature, because there was some loss in weight of the sample due to distillation of volatile liquids. However, the error is not great. This is indicated by the agreement between the final sulphur content calculated from the data of the present experiments and that obtained by analysis of samples used in the electrical measurements mentioned previously. This comparison, printed in Table 1 , shows that the heating in the present investigation had satisfactorily paralleled the conditions during the electrical test and that the procedure and calculations were adequate to furnish the information desired.

\section{RESULTS OF DECOMPOSITION AT CONSTANT TEMPER- ATURE}

In addition to determination of hydrogen sulphide, measurements were made of the amounts of other decomposition products and moisture which resulted from heating vulcanized rubber containing 4, 10, 18 , and 32 per cent sulphur at $136^{\circ}$ and $220^{\circ} \mathrm{C}$. for 200 hours. 


\section{RATE OF LOSS OF HYDROGEN SULPHIDE}

The results show the effects of time, temperature, and composition of samples on the rate of evolution of hydrogen sulphide.

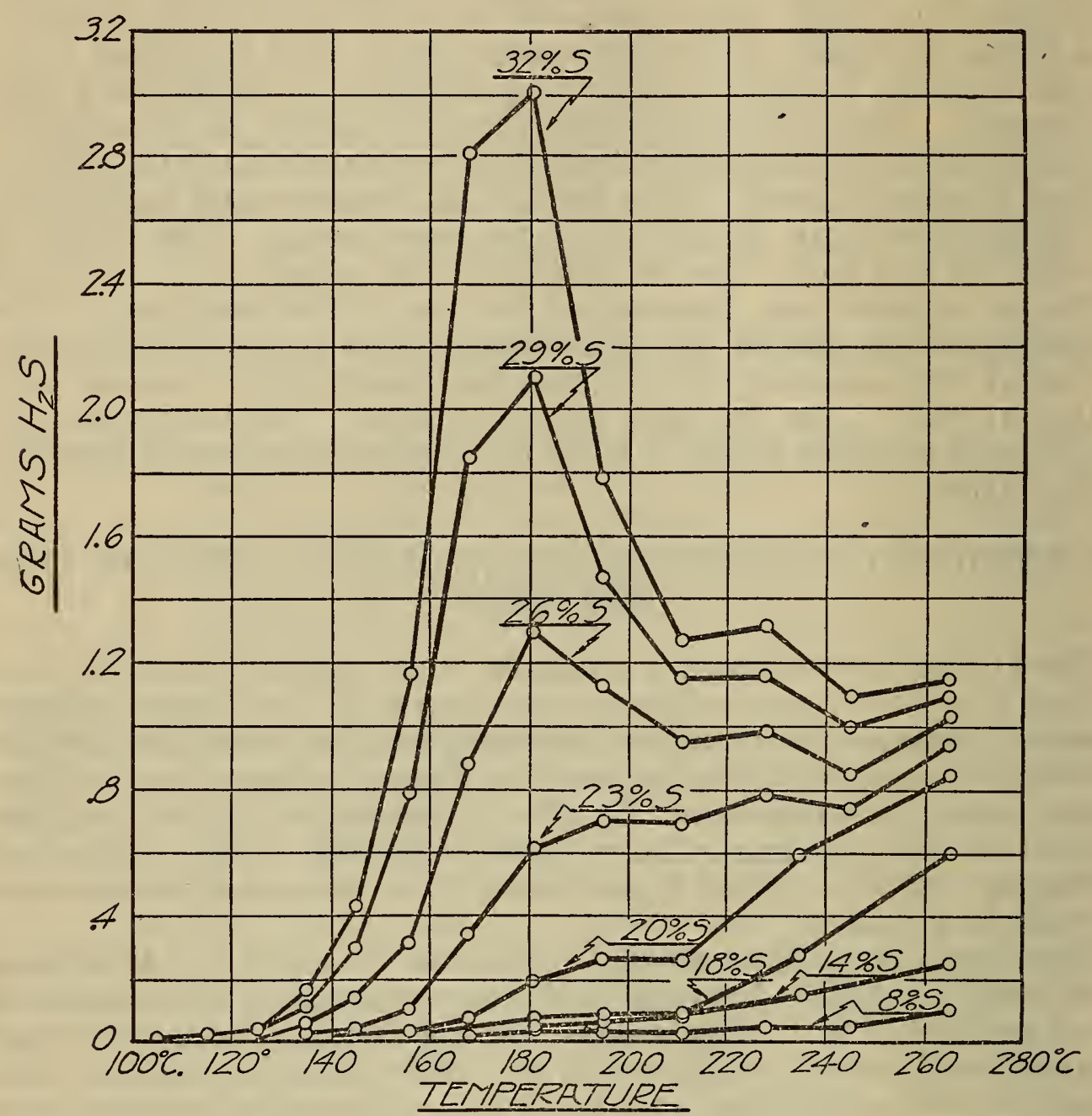

FIGURE 2.-Evolution of hydrogen sulphide from vulcanized rubber during step-by-step heating

Grams of hydrogen sulphide liberated from $100 \mathrm{~g}$ vulcanized rubber heated for eight hours at each temperature indicated. Every sample was started at $105^{\circ}$ and the same sample was carried through to $265^{\circ}$.

\section{(a) EFFECT OF TIME}

For a given composition at each temperature, the rate of loss of hydrogen sulphide, high at first, decreases rapidly during the first few days' heating, but subsequently the decrease becomes slow.

(b) EFFECT OF TEMPERATURE

For a given composition and period of time, the rate increases with rising temperature. 


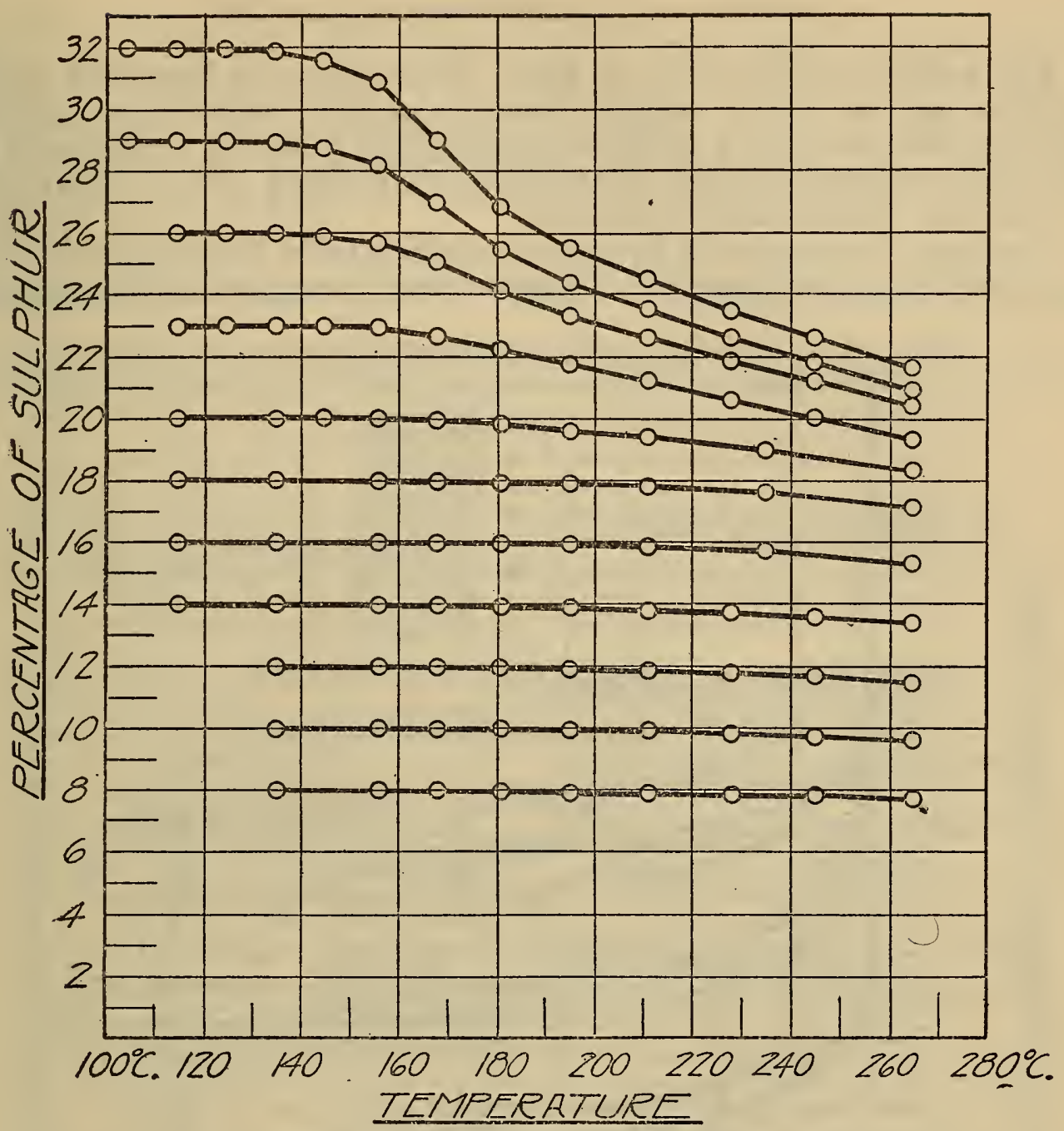

Figdre 3.-Change in sulphur content of vulcanized rubber during step-bystep heating

Samples were heated for 8 hours at each temperature indicated by the rarious points.

Every sample was started at $105^{\circ}$ and the same sample was carried through to $265^{\circ}$.

TABLE 1.-Analysis of electrical test specimens for sulphur compared with sulphur content calculated from the present experiments

\begin{tabular}{|r|r|r|}
\hline & $\begin{array}{c}\text { Sulphur } \\
\text { after heat- } \\
\text { ing cal- } \\
\text { culated } \\
\text { sulphural } \\
\text { from pres- } \\
\text { ent meas- } \\
\text { urements }\end{array}$ & $\begin{array}{c}\text { Total sul- } \\
\text { phur in } \\
\text { specimens } \\
\text { after high } \\
\text { tempera- } \\
\text { ture elec- } \\
\text { trical test }\end{array}$ \\
\hline Per cent & Per cent & Per cent \\
32 & 21.6 & 22.0 \\
29 & 20.9 & 21.5 \\
26 & 20.4 & 20.5 \\
23 & 19.3 & 19.6 \\
20 & 18.3 & 18.1 \\
18 & 17.0 & 16.8 \\
16 & 15.4 & 15.2 \\
14 & 13.4 & 13.4 \\
12 & 11.4 & 11.1 \\
10 & 9.6 & 9.5 \\
8 & 7.7 & 7.8 \\
\hline
\end{tabular}




\section{(c) EFFECT OF COMPOSITION OF SAMPLES}

For a given temperature at equal times, the rate increases as the sulphur content of the rubber becomes greater, with one exception, namely, that there is a noticeable similarity between the 10 and 18 per cent compounds in loss of hydrogen sulphide at $136^{\circ}$. This observation was satisfactorily repeated.

The rate of evolution of hydrogen sulphide from the samples investigated is shown in Figure 4. These curves are started at the point of

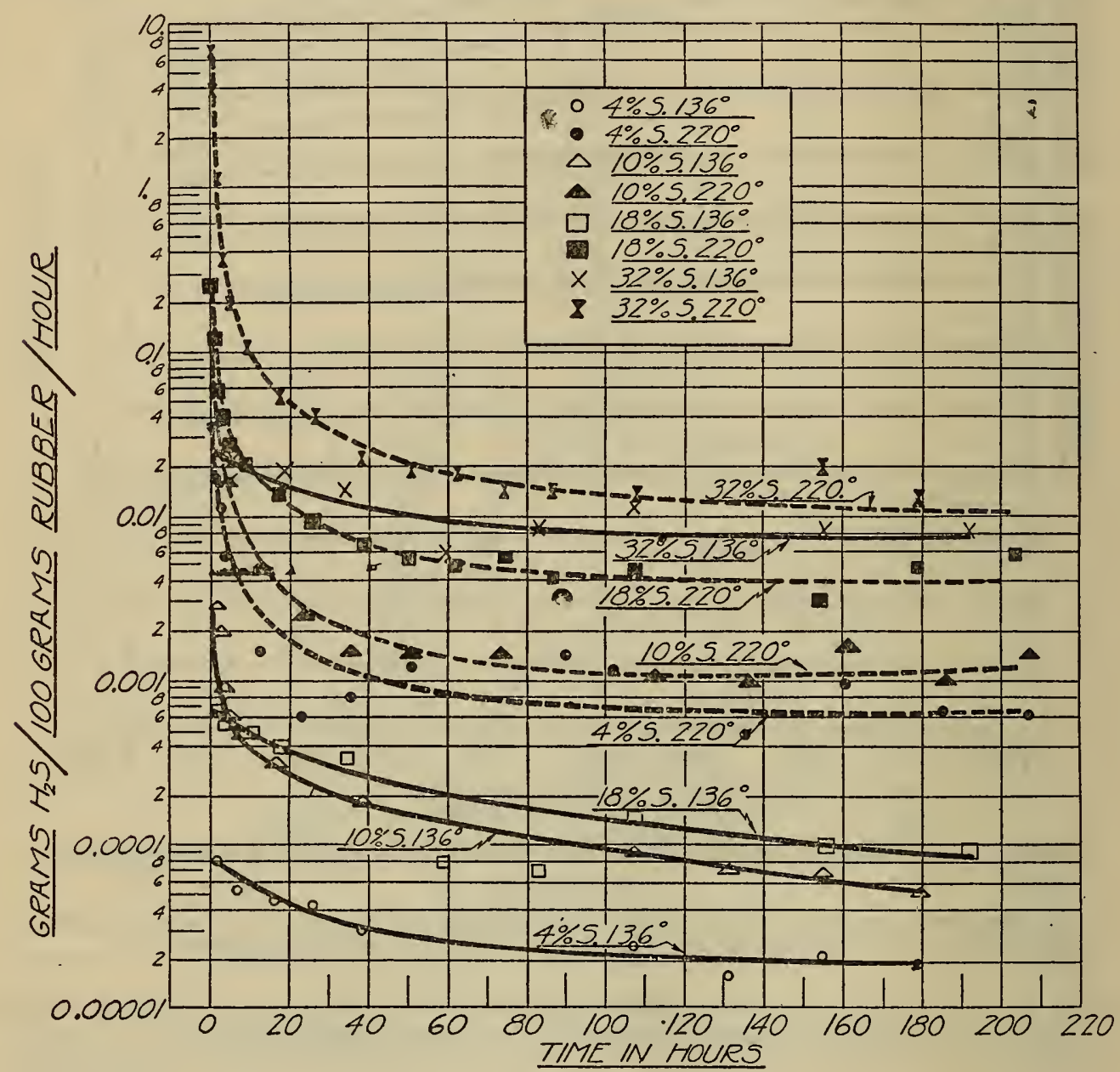

FIGURE 4.-Rate of evolution of hydrogen sulphide from vulcanized rubber heated at $136^{\circ}$ and $220^{\circ} \mathrm{C}$., plotted on a semilogarithmic scale

maximum evolution, an initial increase in rate being disregarded because it must be due only to the heating up of the sample and the approach to a quasi-steady state throughout the apparatus. The percentage of the original weight lost as hydrogen sulphide plotted against the time is given in Figure 5.

\section{OTHER DECOMPOSITION PRODUCTS AND MOISTURE}

Along with the hydrogen sulphide, volatile oils having slight terpenelike odors were formed. At $220^{\circ}$, these oils made up 10 to 40 per cent of the total loss in weight of the samples during 200 hours' heating. There was also a trace of some compound having a faint onionlike odor whicb was never condensed or absorbed by potassium hydroxide or lead acetate. No attempt was made to identify this 
or any of the other organic products. Some moisture ${ }^{4}$ was evolved from the rubber and was measured at the end of each group of experiments in order to be able to account for the entire loss in weight of the samples. The percentage of the original weight obtained in the products from a typical experiment with a 32 per cent compound at $136^{\circ}$ is given in Table 2 , which shows that the total loss was satisfactorily accounted for.

\section{CHARACTERISTICS OF THE RUBBER AFTER HEATING}

The specimens all changed materially in physical properties during the exposure to heat. Compounds which had initially contained up

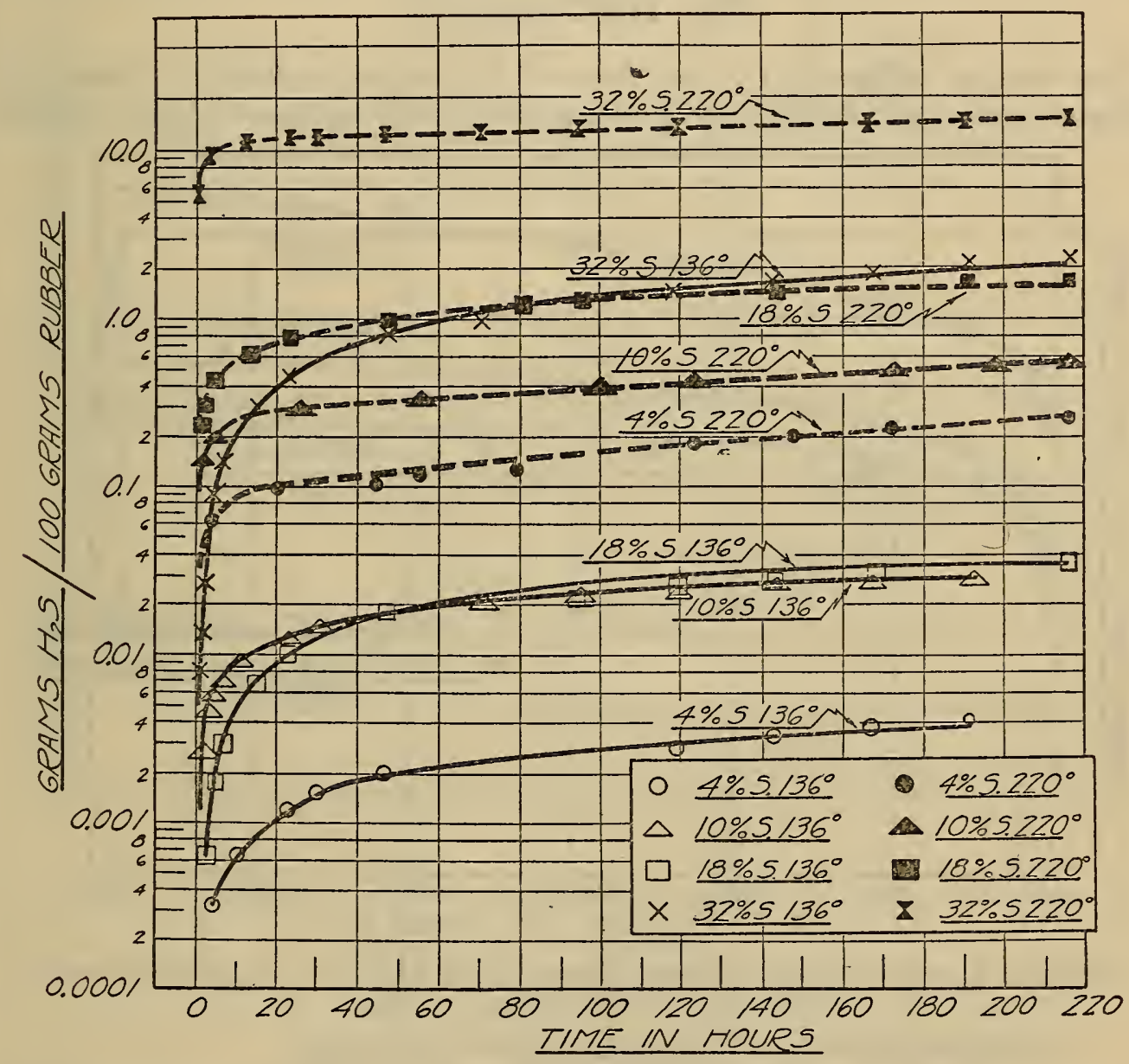

Figure 5.-Percentage loss of hydrogen sulphide at $136^{\circ}$ and $220^{\circ} \mathrm{C}$, plotted on a semilogarithmic scale

to 26 per cent sulphur became translucent and showed a reddish color when samples $1 \mathrm{~mm}$ in thickness were examined in sunlight, whereas all above 12 per cent of sulphur were originally opaque. At the end of the heating, the intermediate and hard rubbers were brittle at room temperature, but became flexible and tacky when warmed. A similar change in properties, less in degree, was evident in the samples of soft rubber. The conversion of vulcanized rubber into thermoplastic materials has been noted by Kemp, ${ }^{5}$ who heated rubber mixed with

\footnotetext{
1 The moisture may have been an impurity or may have come from the thermal decomposition of a small amount of oxidized material in the rubber. For a discussion of the products formed by oxidation of rubber, see Oxidation Studies of Rubber, Gutta-Percha, and Balata Hydrocarbons by A. R. Kemp, W. S. Bishop, and P. A. Lasselle, Ind. Eng. Chem., vol. 23, p. 1444, 1931.

3 A. R. Kemp, U. S. Patent 1638535, Aug. 9, 1927. For a general review of the field of thermoplastic products made from rubber, including patent references, the reader is directed to the Chemistry of Rubber, by Harry L. Fisher, Chem. Rev., vol. 7, No. 1, pp. 94, 112-123, March, 1930.
} 
8 to 16 per cent sulphur to $200^{\circ}$ to $280^{\circ} \mathrm{C}$., and the manufacture of such products from raw rubber is now a commercial process.

TABLE 2.-Percentage of original sample accounted for after a 32 per cent compound was heated 200 hours at $136^{\circ} \mathrm{C}$.

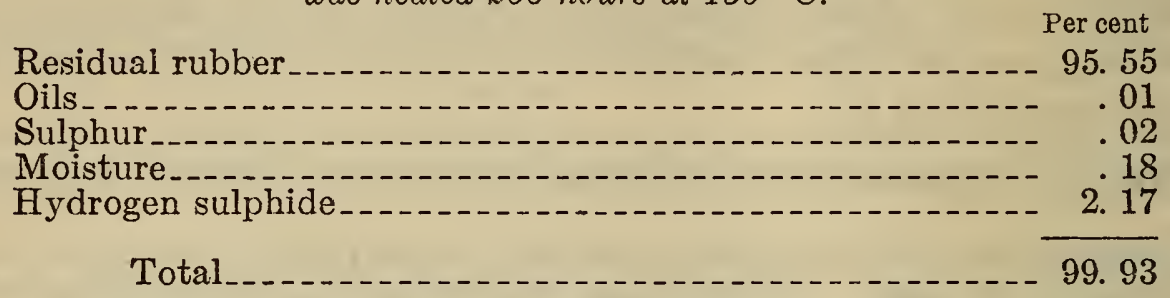

\section{DISCUSSION}

The course followed by the loss of hydrogen sulphide when vulcanized rubber is heated is well established and agrees with the results

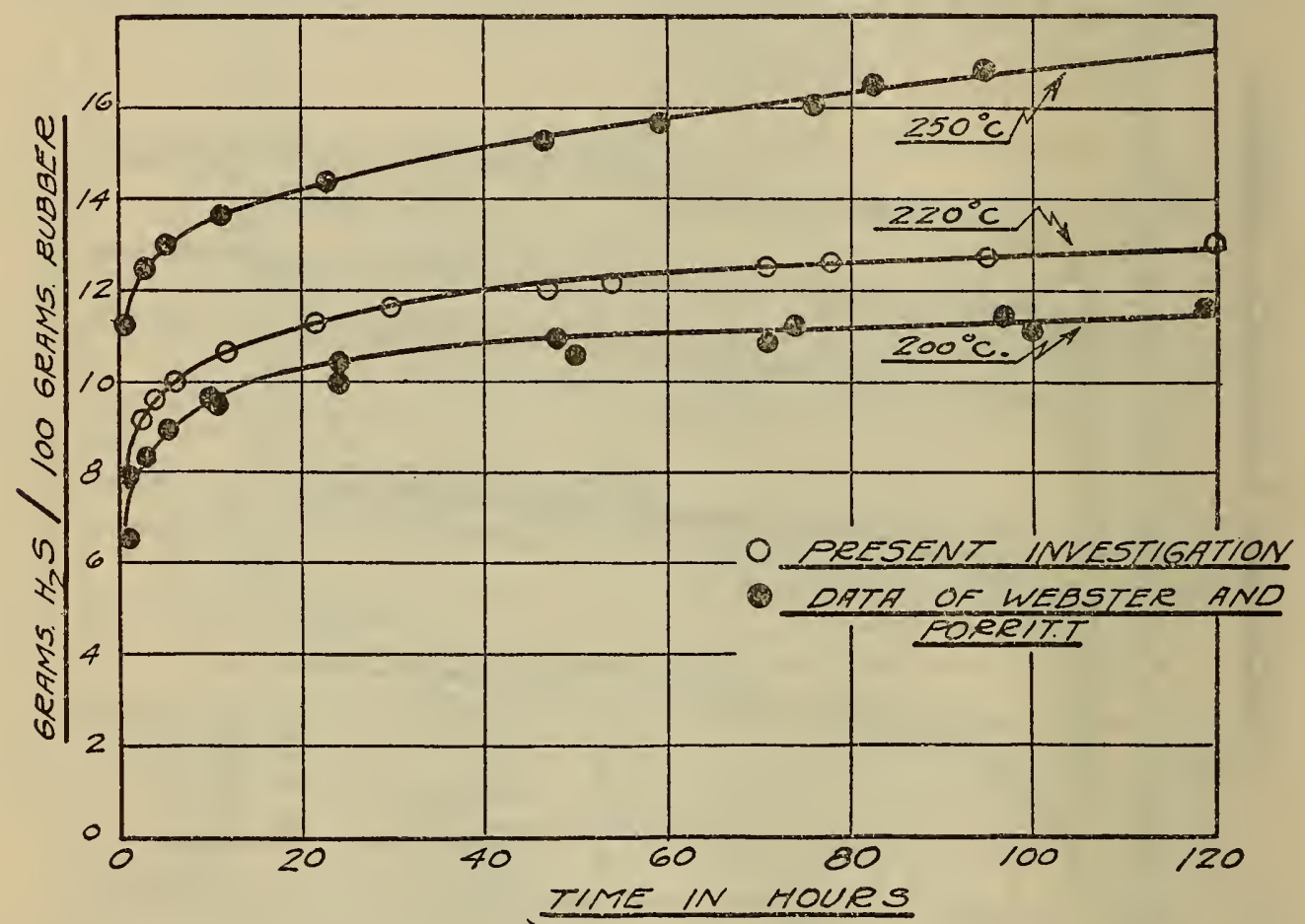

FIGURE 6.-Comparison between present data and those of Webster and Porritt. (See footnote 1, p. 164.)

Loss of hydrogen sulphide from hard rubber at $200^{\circ}, 220^{\circ}$, and $250^{\circ} \mathrm{C}$.

of previous investigations so far as can be told from consideration of the data taken under different conditions. The curve for evolution of hydrogen sulphide from the 32 per cent compound at $220^{\circ}$ lies between similar curves published by Webster and Porritt $^{6}$ for ebonite heated at $200^{\circ}$ and $250^{\circ} \mathrm{C}$. This comparison is shown in Figure 6.

Calculation of the ratio of sulphur lost at the end of 190 hours to the initial sulphur content shows that the percentage of the original sulphur lost at $136^{\circ}$ is greater for the compound containing 10 per cent sulphur than for that containing 18 per cent, and at $220^{\circ}$ is greater for the compound containing 4 per cent sulphur than for that having 10 per cent. On the other hand, the weight of sulphur actually lost per gram of rubber compound was nearly equal for the

- See footnote 1, p. 164. 
10 and 18 per cent compounds at $136^{\circ}$, and was less for the 4 per cent sample than for that containing 10 per cent sulphur at $220^{\circ}$. These calculations are given in Table 3 and the proportionate loss of sulphur is plotted in Figure 7. The similarity in rate and in total percentage of loss at $136^{\circ}$ for the samples containing 10 and 18 per cent sulphur led to a repetition of this experiment over the first 80 hours using

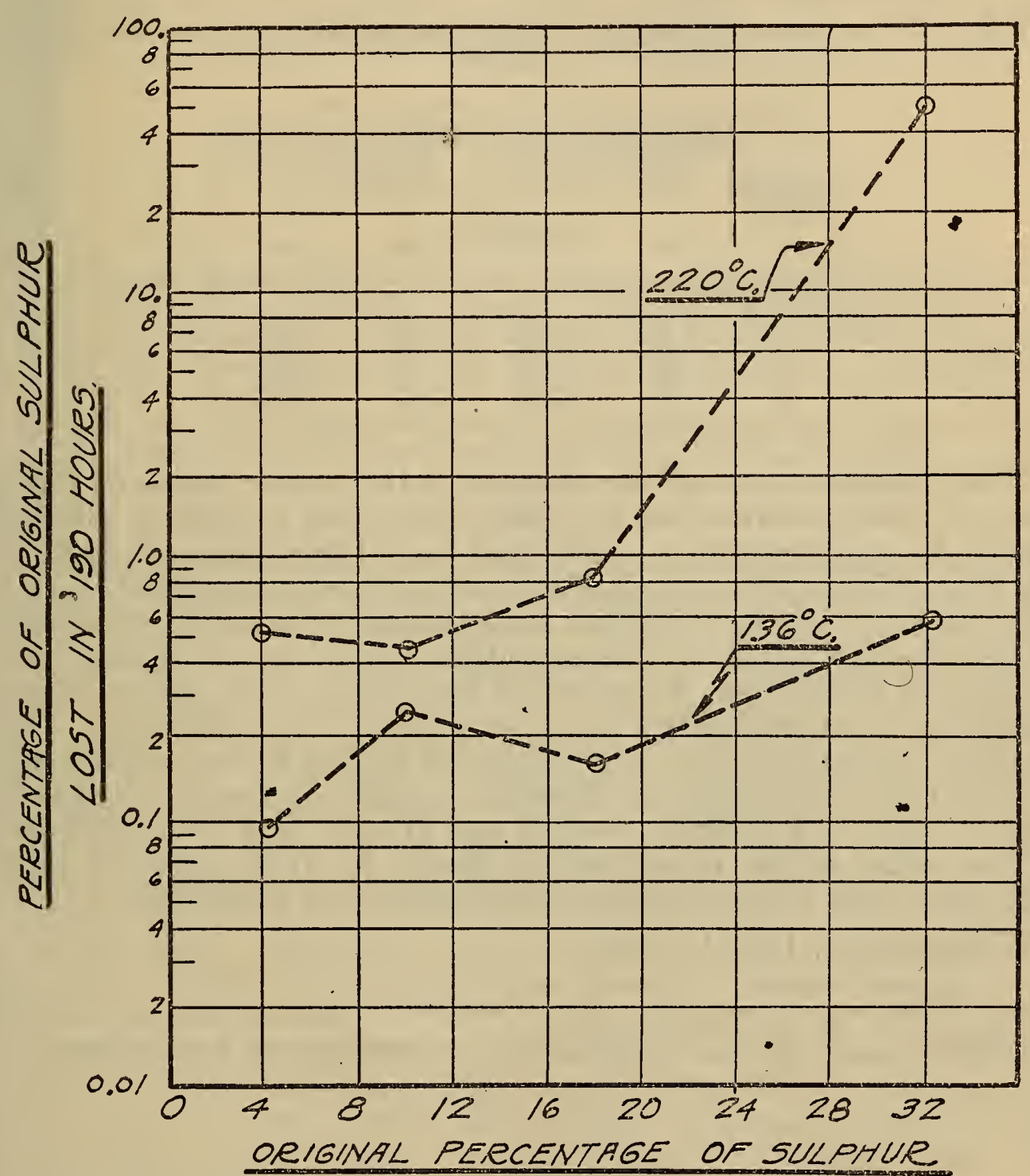

FIgURE 7.-Percentage of original sulphur lost in 190 hours at $136^{\circ}$ and $220^{\circ} \mathrm{C}$., plotted on a semilogarithmic scale as a function of initial sulphur content

other specimens containing the same percentages of sulphur. This determination checked the original observations satisfactorily. Also, an inspection of the data from the earlier experiments showed a distinct similarity in rate of evolution from compounds containing 10 to 18 per cent sulphur at the lower end of the temperature range. These observations can be interpreted as indicating that there may be a range of compositions, varying with the temperature, where rates of decomposition are similar, and where the proportionate loss of sulphur may grow less while the original sulphur content of the 
specimens increases. There may be a fairly sharp break at the end of this range, above which the loss of hydrogen sulphide may-become much more rapid and follow the course expected for the order of ascending sulphur content. The data of the present experiments do not show whether the cases at hand are part of a general phenomenon or only isolated instances.

TABLE 3.-Comparison between loss of hydrogen sulphide and proportionate loss of sulphur

\begin{tabular}{|c|c|c|c|c|}
\hline \multirow{2}{*}{$\begin{array}{l}\text { Original } \\
\text { sulphur }\end{array}$} & \multicolumn{2}{|c|}{$\begin{array}{l}H_{2} S \text { lost at end of } 190 \\
\text { hours as per cent of } \\
\text { original compound }\end{array}$} & \multicolumn{2}{|c|}{$\begin{array}{l}\text { Sulphur lost in } 190 \\
\text { hours as per cent of } \\
\text { original sulphur }\end{array}$} \\
\hline & $136^{\circ}$ & $220^{\circ}$ & $136^{\circ}$ & $220^{\circ}$ \\
\hline $\begin{array}{c}\text { Per cent } \\
4 \\
10 \\
18 \\
32\end{array}$ & $\begin{array}{l}0.004 \\
.029 \\
.033 \\
1.96\end{array}$ & $\begin{array}{r}0.23 \\
.51 \\
1.56 \\
13.92\end{array}$ & $\begin{array}{r}0.094 \\
.26 \\
.17 \\
5.77\end{array}$ & $\begin{array}{r}5.29 \\
4.58 \\
8.15 \\
40.93\end{array}$ \\
\hline
\end{tabular}

The chemical nature of the changes in the rubber molecule during thermal decomposition has not been thoroughly explained, although change in unsaturation as a result of loss of hydrogen sulphide and the effect of heat on vulcanized rubber has been commented upon by Winkelmann, ${ }^{7}$ and by the other investigators previously mentioned. ${ }^{8}$ A few determinations of unsaturation made on the rubber after heating in the present experiments have not given any additional insight into the mechanism of the chemical changes involved. This phase of the problem may be investigated further at some future time.

Since this manuscript was prepared, a paper on the pyrolysis products of ebonite by Midgley, Henne, and Shepard has been published. ${ }^{9}$

The author wishes to express his thanks to A. H. Scott for assistance with some of the measurements reported in this paper.

Washington, June 1, 1932.

7 H. A. Winkelmann, Ind. Eng. Chem., vol. 18, p. 1163, 1926.

8 See footnote 1, p. 164 , and footnote 5 , p. 171 .

- T. Midgley, jr., A. L. Henne, and A. F. Shepard, J. Am. Chem. Soc., vol. 54, p. 2953, 1932. 